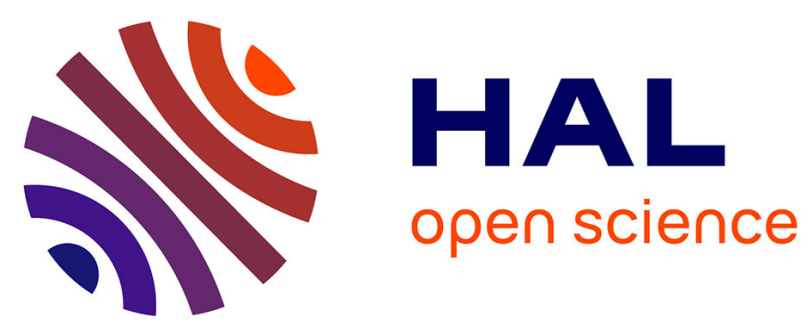

\title{
Electric dipole, polarizability and structure of cesium chloride clusters with one-excess electron
}

\author{
A. Jraij, Abdul-Rahman Allouche, Franck Rabilloud, M. Korek, M. \\ Aubert-Frécon, D. Rayane, I. Compagnon, R. Antoine, M. Broyer, Ph. \\ Dugourd
}

\section{To cite this version:}

A. Jraij, Abdul-Rahman Allouche, Franck Rabilloud, M. Korek, M. Aubert-Frécon, et al.. Electric dipole, polarizability and structure of cesium chloride clusters with one-excess electron. Chemical Physics, 2006, 322 (3), pp.298 - 302. 10.1016/j.chemphys.2005.09.033 . hal-01674054

\section{HAL Id: hal-01674054 https://hal.science/hal-01674054}

Submitted on 17 Jan 2022

HAL is a multi-disciplinary open access archive for the deposit and dissemination of scientific research documents, whether they are published or not. The documents may come from teaching and research institutions in France or abroad, or from public or private research centers.
L'archive ouverte pluridisciplinaire HAL, est destinée au dépôt et à la diffusion de documents scientifiques de niveau recherche, publiés ou non, émanant des établissements d'enseignement et de recherche français ou étrangers, des laboratoires publics ou privés. 


\title{
Electric dipole, polarizability and structure of cesium chloride clusters
}

\section{with one excess electron.}

\author{
A. Jraij ${ }^{1}$, A. R. Allouche ${ }^{1}$, F. Rabilloud ${ }^{1}$, M. Korek ${ }^{2}$, M. Aubert-Frécon ${ }^{1}$, D. Rayane ${ }^{1}$, I. \\ Compagnon $^{1}$, R. Antoine ${ }^{1}$, M. Broyer ${ }^{1}$, Ph. Dugourd ${ }^{1}$. \\ ${ }^{1}$ Laboratoire de Spectrométrie Ionique et Moléculaire, UMR 5579, CNRS et \\ Université Lyon1, Bâtiment Alfred Kastler, F69622 Villeurbanne Cedex, France. \\ ${ }^{2}$ Beirut Arab University, P. O. Box 11-5020, Beirut, Lebanon
}

\begin{abstract}
.
The measurement of the electric dipole of gas phase one-excess electron $\mathrm{Cs}_{n} \mathrm{Cl}_{n-1}$ clusters is reported together with a theoretical ab initio prediction of stable structures, dipole moments and electronic polarizabilities for these species in their ground state. Results are in agreement with $\mathrm{NaCl}$ cubic structures.
\end{abstract}

Corresponding author:

Dr Driss Rayane

Tel: +33472448226

Fax: +33472431507

e-mail: rayane@lasim.univ-lyon1.fr 


\section{Introduction.}

Alkali-halide clusters have received a considerable experimental and theoretical attention [1-11] partly because they are relatively easy to form and because their ionic bonding character can be described through simple models. An important goal of these investigations is to determine the most stable isomers for each cluster size and to follow the size evolution of selected properties, with the final aim of studying the emergence of bulk behavior from the molecular limit. In $\mathrm{NaF}$ and $\mathrm{NaCl}$ clusters, which have been extensively studied, the cubic structure of the solid emerges in the very small sizes. The structure of cesium chloride bulk is different (height-fold coordinated $\mathrm{CsCl}$ lattice structure) and a competition between $\mathrm{NaCl}$ and $\mathrm{CsCl}$ structures has recently been evidenced in medium size clusters $[12,13]$. Moreover, when an extra electron is added to $\mathrm{NaCl}$ or $\mathrm{NaF}$ clusters, their ionic framework mainly formed of small cubic nanocrystals can accommodate the excess electron in several ways as classified in $[7,14,15]$. For $\mathrm{CsCl}$ clusters, the large size of the electronic inner shells may induce different localizations of the excess electron.

In this paper, we present the results of a joint experimental and theoretical investigation of the electric dipole of the one-excess electron clusters $\mathrm{Cs}_{n} \mathrm{Cl}_{n-1}(\mathrm{n}=6-18)$. This property provides an insight in the various atomic arrangements and is sensitive to the excess electron density distribution. Experimental dipoles are investigated by deflection measurements of a molecular beam in a static inhomogeneous electric field, as previously reported for $\mathrm{Cs}_{\mathrm{n}} \mathrm{Br}_{\mathrm{n}-1}$ [16] and for $\mathrm{Na}_{\mathrm{n}} \mathrm{F}_{\mathrm{n}-1}$ clusters [17]. Stable geometrical structures have 
been determined for the lowest-energy isomer from Hartree-Fock energy calculations. For these equilibrium isomers, the permanent dipole moment and the static dipolar polarizability were evaluated and compared to experimental data.

\section{Experiment and results.}

Electric dipoles of free neutral clusters are investigated by deflecting a molecular beam in an inhomogeneous electric field. The experiment consists in a laser vaporization source coupled to an electric deflector and a position sensitive mass spectrometer. Alkali halide clusters are produced by ablation of a salt target $(99 \% \mathrm{CsCl}$ purchased from Acros Organics) with the third harmonic of a $\mathrm{Nd}^{3+}:$ YAG laser $(355 \mathrm{~nm})$. The clusters are carried by a helium pulse and leave the source through a $5 \mathrm{~cm}$ long nozzle. After passing through two skimmers, the beam is collimated by two rectangular slits $(0.5 \mathrm{~mm}$ width $)$ and travels through the electric deflector ("two-wires" electric field configuration with $F_{Z}=1.63 \times 10^{7}$ $\mathrm{Vm}^{-1}$ and $\nabla F_{Z}=2.82 \times 10^{9} \mathrm{Vm}^{-2}$ for $\mathrm{V}=27 \mathrm{kV}$ across the two poles). Clusters are ionized one meter beyond the deviator in the extraction region of a position sensitive time-offlight mass spectrometer. The mass of the cluster and the profile of the beam are obtained from the arrival time at the detector. For each size, the beam profile is measured as a function of the electric field in the deflector. A mechanical chopper located in front of the first slit allows us to select and measure the velocity $v$ of the beam. The deflection of a molecule is given by:

$$
d=K \frac{\left\langle\mu_{Z}\right\rangle}{m v^{2}} \nabla F_{Z}
$$

where $Z$ is the axis of the electric field, $\nabla F_{Z}$ its gradient, $m$ the mass of the cluster and $K$ a 
geometrical factor. $\left\langle\mu_{Z}\right\rangle$ is the time-averaged value of the $Z$ component of the dipole in the electric field.

Salt clusters were ionized with two different harmonics of a second $\mathrm{Nd}^{3+}: \mathrm{YAG}^{\mathrm{A}}$ laser ( $\lambda=266$ and $\lambda=532 \mathrm{~nm})$. At $\lambda=266 \mathrm{~nm}, \mathrm{Cs}_{\mathrm{n}} \mathrm{Cl}_{\mathrm{n}-1}{ }^{+}$clusters with $\mathrm{n}=6,8,9,12,14,15,16$, 18 and 20 are observed in the mass spectrum. The majority of sizes that are not observed in mass spectra $(\mathrm{n}=5,7,10,11,13,17,19, .$.$) have, according to the literature [9] and to$ the present calculations, a cubic structure with an alkali tail. Two other families of peaks, corresponding to $\mathrm{Cs}_{\mathrm{n}} \mathrm{Cl}_{\mathrm{n}-2}{ }^{+}$and $\mathrm{Cs}_{\mathrm{n}} \mathrm{Cl}_{\mathrm{n}-4}{ }^{+}$series, are also observed but with weaker intensities. These species disappear as the nozzle is heated, while their intensity increases when the nozzle is cooled down. At $\lambda=532 \mathrm{~nm}$, a single intense peak corresponding to $\mathrm{Cs}_{14} \mathrm{Cl}_{13}{ }^{+}$is observed.

Deflection measurements were performed using $\lambda=266 \mathrm{~nm}$ for every size. For $\mathrm{n}=14$, measurements at $\lambda=266$ and $\lambda=532 \mathrm{~nm}$ are similar. The profiles obtained with the electric field turned on are globally deflected towards the positive $Z$ direction (high electric field region in the deflector). For $\mathrm{Cs}_{14} \mathrm{Cl}_{13}$, a slight broadening is superimposed to the deflection. For each size, the average deviation $d$ is determined by fitting the experimental profiles with gaussian shapes. The deviation is studied as a function of the field. It is proportional to the square of the electric field. For each cluster, it is then possible to define an electric susceptibility $\chi$ :

$$
\chi=\frac{\left\langle\mu_{Z}\right\rangle}{F_{Z}},
$$


and

$$
d=\chi K \frac{F_{Z} \nabla F_{Z}}{m v^{2}}
$$

The deflection experiments were calibrated on the lithium atom which polarizability is known with a good accuracy $\left(24.3 \pm 0.5 \AA^{3}\right)$ [18]. The precision on the experimental susceptibility depends on the calibration, on the velocity measurement and on the deflection measurement. This leads, depending on the size, to a precision of 9 to $18 \%$ on the absolute value. Experimental susceptibilities obtained at room temperature from Eq. (3.) are reported in Fig. 1 and Table 1. They range from $\sim 200$ to $4250 \AA^{3}$ with strong size dependence. The same pattern was observed for cesium bromide and sodium fluoride clusters.

The susceptibility is related to the electric dipole by the Langevin-Debye formula $[19,20]:$

$\chi=\frac{\left\langle\mu^{2}\right\rangle_{T}}{3 k T}+\alpha$

where $\left\langle\mu^{2}\right\rangle_{T}$ is the average value of the fluctuation of the square of the dipole at equilibrium at temperature $\mathrm{T}$ without electric field and $\alpha$ is the average static polarizability of the cluster.

\section{Theoretical approach and results.}

\subsection{Calculation method}


We report here first calculations on $\mathrm{Cs}_{n} \mathrm{Cl}_{n-1}$ cesium chloride clusters with one excess electron. They are isovalent to the previously investigated sodium fluoride $\mathrm{Na}_{\mathrm{n}} \mathrm{F}_{\mathrm{n}-1}$ clusters [17]. For any size $n=2-18$ geometry, optimizations were performed through a Hartree-Fock (HF) approach. Cesium and chlorine atoms were treated as 9- and 7valence electron systems respectively, via pseudopotentials of semi-local type taken from the literature $[21,22]$. LANL2DZ basis sets were selected for both cesium $(8 \mathrm{~s} 6 \mathrm{p} /[3 \mathrm{~s} 3 \mathrm{p}])$ and chlorine $(3 \mathrm{~s} 3 \mathrm{p} /[2 \mathrm{~s} 2 \mathrm{p}])$ atoms, augmented respectively by one d function (with exponent: 0.069803) for $\mathrm{Cs}$ and one $\mathrm{d}$ (exponent: 0.44536) and one $\mathrm{f}$ (exponent: 1.18721461) functions for $\mathrm{Cl}$, after tests on the calculated equilibrium distance the permament dipole of the $\mathrm{CsCl}$ diatomic molecule.

In order to select initial geometries for a given size n, we first built structures of related clusters with no excess electron i.e $\mathrm{Cs}_{n} \mathrm{Cl}_{n}$ and $\left(\mathrm{Cs}_{n} \mathrm{Cl}_{n-1}\right)^{+}$clusters. For these species, the total energy was calculated with a Born-Mayer potential using the parameters given in Ref. [23]. Starting from an arbitrary initial geometry generated by a Monte Carlo algorithm, the total energy was minimized with respect to ionic positions thus providing a local minimum. Around 200 quenches were performed for each size. Then some $(\sim 20)$ of these configurations (corresponding to the lowest local minima or obtained several times from different initial choices ...) were selected to be used as input data to determine the lowest-energy structures at $\mathrm{HF}$ level for the clusters $\mathrm{Cs}_{\mathrm{n}} \mathrm{Cl}_{\mathrm{n}-1}$ under investigation. For filled cuboids or cuboids with adatom geometrical configurations previously derived for the corresponding ionized species $\left(\mathrm{Cs}_{n} \mathrm{Cl}_{n-1}\right)^{+}$were directly used as initial data in the minimization process of the total energy for $\mathrm{Cs}_{n} \mathrm{Cl}_{n-1}$ evaluated this time at $\mathrm{HF}$ level. For 
cuboids with vacancies geometrical configurations previously derived for $\mathrm{Cs}_{n} \mathrm{Cl}_{n}$ were used as initial guess for the geometry optimization of $\mathrm{Cs}_{\mathrm{n}} \mathrm{Cl}_{\mathrm{n}-1}$ at $\mathrm{HF}$ level by removing a halogen atom from various positions. The geometrical configuration corresponding to the smallest energy was retained as probable structure for $\mathrm{Cs}_{n} \mathrm{Cl}_{n-1}$. Calculations were performed using GAUSSIAN98 [24] through the graphical interface GABEDIT [25].

\subsection{Theoretical results.}

\subsubsection{Lowest-energy equilibrium geometries}

Lowest-energy structures are found to be of cuboidal form for any size considered here. They display either an anion vacancy: F-center $(n=6,8,12,15,16,18)$ or a Cs adatom: cesium-tail $(n=7,10,11,13,17)$, except for $n=14$ which represents the first possible filled cube. They are shown in Fig. 1 for sizes that were experimentally observed, together with the excess electron density as well as the dipole moment represented by an arrow.

3.2.2 Dipole moment, static dipolar polarizability and electrical susceptibility.

The permanent dipole moment $\mu$ as well as the three cartesian components of the static dipolar polarizability $\alpha_{\mathrm{ii}}$ with $\mathrm{i} \in\{\mathrm{x}, \mathrm{y}, \mathrm{z}\}$ and the isotropic value $\alpha=\left(\alpha_{\mathrm{xx}}+\alpha_{\mathrm{yy}}+\alpha_{\mathrm{zz}}\right) / 3$ have been evaluated for clusters in their lowest-energy structure previously determined. From these calculated values, the susceptibility $\chi$ has been determined for each size using the Langevin-Debye formula (eq. 3) and $\mathrm{T}=300 \mathrm{~K}$.

Calculated values of $\mu, \alpha$ and $\chi$ are reported in Table 1 . The calculated susceptibility is 
shown in Fig. 1 comparatively to our available experimental results. Except for the size $\mathrm{n}=14$, the general trends of the experimental results (evolution with the size $\mathrm{n}$ and absolute values) are reproduced in a satisfactory way by the calculated values. For $n=6,8$, 15 calculated values for $\chi$ are inside the experimental uncertainty range. For $n=9,12,16$ the averaged relative error $\delta$ between calculated and experimental values of $\chi$ is $\sim 16 \%$, which can be considered as a satisfactory result not too far from the averaged experimental error for these three sizes $(\sim 12 \%)$. For $\mathrm{Cs}_{18} \mathrm{Cl}_{17}$, the experimental susceptibility is very large $\left(4200 \AA^{3}\right)$. The calculated value is larger by an amount of $\sim 30 \%$ than the experimental value (see discussion below). As for $n=14$, due to the huge calculated value of $\mu$ (32.772 Debye) together with a large value of $\alpha\left(620 \AA^{3}\right)$ we obtained $\chi=9264 \AA^{3}$, a value which appears to be meaningless when compared to our experimental value $1945 \AA^{3}$. At the present HF level, the lowest-energy structure of $\mathrm{Cs}_{14} \mathrm{Cl}_{13}$ is a cube of symmetry $\mathrm{C}_{3 \mathrm{v}}$ with the excess electron localized on a corner $\mathrm{Cs}$ atom. This explains both the large value of $\mu$ and the large value of $\alpha$. This structure is in competition with two geometries with a delocalized electron $\left(\mathrm{O}_{\mathrm{h}}\right.$ structure and surface state). These structures are obtained by small deformations of the cube and have much lower permanent electric dipoles. At the present level of calculation, these structures correspond to saddle points on the potential energy surface. For this size, vibronic couplings clearly cannot be ignored. Moreover, correlation effects are expected to be important for such configurations. Because they are ignored at HF level, the present description of $\mathrm{Cs}_{14} \mathrm{Cl}_{13}$ is definitely meaningless.

\section{Discussion and conclusion.}


From the overall agreement between experimental and calculated values of the electrical susceptibility of the lowest-energy structures of $\mathrm{Cs}_{n} \mathrm{Cl}_{n-1}$, it may be inferred that measurements correspond to cuboid structures for these species. Nevertheless, it may be interesting to have an insight into the limitation of this comparison and on the possibility of distinguishing from an isomer to another for a given size. Then, for 3 particular sizes, two $(n=8,15)$ for which the agreement is quite satisfactory and one $(n=18)$ for which the agreement is rather bad, we discuss in details the structure and susceptibility of all isomers that were obtained in a transition energy range of $\sim 1 \mathrm{eV}$. Calculated isomers for these three sizes are shown in Fig. 2.

For $\mathrm{Cs}_{8} \mathrm{Cl}_{7}, 2$ low-lying $(4 \times 2 \times 2)$ cuboid structures with one missing chlorine ion are obtained. Isomer (c) is built up from 2 layers of $\mathrm{Cs}_{3} \mathrm{Cl}_{3}$ plus one $\mathrm{CsCl}_{2}$. Isomer (d) displays a two layer octagonal structure with an anion vacancy. Isomer (e) may be described as a widely open sheet. Electric susceptibility calculated for the most stable structure is in perfect agreement with the experimental value. The other isomers have a susceptibility that is higher. In particular, the sheet (structure e) has a susceptibility more than one order magnitude larger than the experimental value.

For $\mathrm{Cs}_{15} \mathrm{Cl}_{14}, 10$ low-lying structures have been obtained as stable geometries in the energy range $\Delta \mathrm{E} \leq 0.51 \mathrm{eV}$. Isomers $(\mathrm{a}, \mathrm{c}, \mathrm{d}, \mathrm{e}, \mathrm{i}, \mathrm{j}$ ) have a similar structure, they are cuboids with 5 layers of $\mathrm{Cs}_{3} \mathrm{Cl}_{3}$ and an anion vacancy located at different positions. Isomer (b) is a $3 \times 3 \times 3$ cube with a $\mathrm{CsCl}$ on one edge, the excess electron localizes on the anion vacancy. Isomers $(\mathrm{g}, \mathrm{h})$ have the same structure with 2 layers of $\mathrm{Cs}_{6} \mathrm{Cl}_{6}$ plus an 
overhead layer of $\mathrm{Cs}_{3} \mathrm{Cl}_{3}$ with an anion vacancy situated at a corner of the $\mathrm{Cs}_{3} \mathrm{Cl}_{3}$ layer $(\mathrm{g})$ or at a corner of the second layer of $\mathrm{Cs}_{6} \mathrm{Cl}_{6}(\mathrm{~h})$. The calculated susceptibility for these isomers varies from 327 to $8570 \AA^{3}$. The value for isomer (a) $\left(1236 \AA^{3}\right)$ is within the experimental error bar $\left(1160 \pm 133 \AA^{3}\right)$. Isomer (b) has a huge permanent dipole which results in a large susceptibility $\left(8570 \AA^{3}\right)$ induced by the localization of the excess electron. Due to the large difference in susceptibility, isomer (a) and (b) would be spatially separated after deflection. The analysis of the deflected peak shows that there is no isomer (b) in the beam.

For the two above sizes, comparison of the experimental and theoretical results allows a precise determination of the cluster geometry. This is true for all sizes inferior or equal to 12. This is a not the case for the third example $\left(\mathrm{Cs}_{18} \mathrm{Cl}_{17}\right)$. Calculated isomers are shown in Fig. 2. Excepted isomer $(\mathrm{g})$, they are $(3 \times 3 \times 5)$ cuboids with an anion vacancy located at different positions. All these structures have a large electric dipole. The particularly large dipoles calculated for this family of cuboid structures is in agreement with the high value measured for this size (see Fig. 1). However the experimental value $\left(4244 \AA^{3}\right)$ is not in agreement with the one calculated for isomer (a) $\left(5577 \AA^{3}\right)$. This may be due to a non accurate calculation of the relative energy between different isomers and isomer (a) may not be the most stable structure (isomer (b) has a calculated susceptibility ranging at the bottom of the experimental error bar). Or, the dipole of isomer (a) may be over estimated. A possible explanation for the overestimation of the calculated value is the lack of correlation. One cannot also exclude for large sizes a mixing of isomers in the beam [7]. The generation of isomers (b) to (f) from isomer (a) only implies the displacement of a 
11

vacancy that might occur during the travel through the deflector, which is different for example from size 15 (in this case a complete reconstruction is needed to go from structure (a) to structure (b)).

In conclusion, we report here the first measurement and calculation of electric dipole properties of gas phase $\mathrm{Cs}_{n} \mathrm{Cl}_{\mathrm{n}-1}$ cesium chloride clusters. The experimental results are in global agreement with $\mathrm{NaCl}$ cubic structures. For small sizes, the comparison between experiment and theory allows a precise determination of the most stable structure. For large sizes, in particular for those with a very large dipole, the comparison is clearly limited by the precision of the calculation. 


\section{References}

[1] J. Diefenbach, T. P. Martin: J. Chem. Phys. 83 (1985) 4585.

[2] R. Pflaum, K. Sattler, E. Recknagel: Phys. Rev. B 33 (1986) 1522.

[3] E. C. Honea, M. L. Homer, P. Labastie, R. L. Whetten: Phys. Rev. Lett. 63 (1989) 394.

[4] P. Xia, L. A. Bloomfield: Phys. Rev. Lett. 70 (1993) 1779.

[5] C. Ochsenfeld, R. Ahlrichs: J. Chem. Phys. 101 (1994) 5977.

[6] V. Bonacic-Koutecky, J. Pittner, J. Koutecky: Chem. Phys. 210 (1996) 313.

[7] P. Dugourd, R. R. Hudgins, M. F. Jarrold: Chem. Phys. Lett. 267 (1997) 186.

[8] A. Aguado, A. Ayuela, J. M. Lopez, J. A. Alonso: Phys. Rev. B 58 (1998) 9972.

[9] G. Durand, J. Giraud-Girard, D. Maynau, F. Spiegelmann, F. Calvo: J. Chem. Phys. 110 (1999) 7871.

[10] G. Durand, F. Spiegelmann, P. Poncharal, P. Labastie, J. M. L'Hermite, M. Sence: J. Chem. Phys. 110 (1999) 7884.

[11] F. K. Fatemi, A. J. Dally, L. A. Bloomfield: Phys. Rev. Lett. 84 (2000) 51.

[12] S. Krückeberg, D. Schooss, M. Maier-Borst, J. H. Parks: Phys. Rev. Lett. 85 (2000) 4494.

[13] A. Aguado: Phys. Rev. B 62 (2000) 13687.

[14] U. Landman, D. Scharf, J. Jortner: Phys. Rev. Lett. 54 (1985) 1860.

[15] G. Durand, F. Spiegelmann, P. Labastie, J. M. L'Hermite, P. Poncharal: Phys. Rev. Lett. 79 (1997) 633. 
[16] D. Rayane, R. Antoine, P. Dugourd, M. Broyer: J. Chem. Phys. 113 (2000) 4501.

[17] D. Rayane, I. Compagnon, R. Antoine, M. Broyer, P. Dugourd, P. Labastie, J. M. L'Hermite, A. le Padellec, G. Durand, F. Calvo, F. Spiegelman, A. R. Allouche: J. Chem. Phys. 116 (2002) 10730.

[18] R. W. Molof, H. L. Schwartz, T. M. Miller, B. Bederson: Phys. Rev. A 10 (1974) 1131.

[19] J. H. Van vleck: Phys. Rev. 30 (1927) 31.

[20] P. Debye: Polar molecules, Dover Publications, New York, 1929.

[21] W. R. Wadt, P. J. Hay: J. Chem. Phys 82 (1985) 284.

[22] P. J. Hay, W. R. Wadt: J. Chem. Phys 82 (1985) 299.

[23] D. O. Welch, O. W. Lazareth, G. J. Dienes: J. Chem. Phys. 64 (1976) 835.

[24] M. J. Frisch, G. W. Trucks, H. B. Schlegel, P. M. W. Gill, B. G. Johnson, M. A. Robb, J. R. Cheeseman, T. Keith, G. A. Petersson, J. A. Montgomery, K. Raghavachari, M. A. Al-Laham, V. G. Zakrzewski, J. V. Ortiz, J. B. Foresman, C. Y. Peng, P. Y. Ayala, W. Chen, M. W. Wong, J. L. Andres, E. S. Replogle, R. Gomperts, R. L. Martin, D. J. Fox, J. S. Binkley, D. J. DeFrees, J. Baker, J. P. Stewart, M. Head-Gordon, C. Gonzales, J. A. Pople: GAUSSIAN98(Revision A.6), Pittsburgh, PA, 1998.

[25] GABEDIT is a graphical user interface for the use of MOLPRO and GAUSSIAN available at the website: http://lasim.univlyon 1.fr/allouche/gabedit. 
Figure captions.

Figure 1: Experimental (I) and calculated (o) susceptibilities for $\mathrm{Cs}_{n} \mathrm{Cl}_{\mathrm{n}-1}$ clusters (between $n=6$ and 20). The structure of lowest energy obtained for each size is shown. For each structure, the direction of the electric dipole is indicated by an arrow and an isosurface of the excess electron density is plotted (identical iso-values (0.02) were used).

Figure 2: Low energy isomers obtained at the HF level for sizes 8,15 and 18. For each structure, the direction of the electric dipole is indicated by an arrow and an iso-surface of the excess electron density is plotted (identical iso-values (0.02) were used). The relative energies and the susceptibilities are given. 
Table 1

Calculated and experimental susceptibilities $\chi$ of $\mathrm{Cs}_{n} \mathrm{Cl}_{\mathrm{n}-1}$ clusters. Calculated average polarizability $\left(\alpha_{c a l}\right)$ and total permanent dipole moment $\left(\mu_{c a l}\right)$ are also given. Calculated data are given for the lowest energy isomer and $\mathrm{T}=300 \mathrm{~K}$ is used to calculate the susceptibility (see Eq. 4).

\begin{tabular}{|c|c|c|c|c|c|}
\hline$n$ & Structure & $\begin{array}{l}\alpha_{c a l} \\
\left(\AA^{3}\right) \\
\end{array}$ & $\begin{array}{c}\mu_{c a l} \\
\text { (Debye) }\end{array}$ & $\begin{array}{l}\chi_{c a l} \\
\left(\AA^{3}\right) \\
\end{array}$ & $\begin{array}{l}\chi \exp \\
\left(A^{3}\right) \\
\end{array}$ \\
\hline 6 & $2 \times 2 \times 3-C 1$ & 145 & 3.4 & 238 & $233 \pm 24$ \\
\hline 8 & $2 \times 2 \times 4-C 1$ & 155 & 3.9 & 278 & $274 \pm 39$ \\
\hline 9 & $2 \times 3 \times 3-C 1$ & 152 & 11.2 & 1154 & $953 \pm 106$ \\
\hline 12 & $2 \times 3 \times 4+C s$ & 164 & 4.9 & 353 & $400 \pm 44$ \\
\hline 14 & $3 \times 3 \times 3\left(C_{3 v}\right)$ & 623 & 32.8 & 9263 & $1945 \pm 186$ \\
\hline 15 & $2 \times 3 \times 5-\mathrm{Cl}$ & 177 & 11.5 & 1236 & $1160 \pm 133$ \\
\hline 16 & $2 \times 4 \times 4-C l$ & 182 & 5.2 & 398 & $477 \pm 68$ \\
\hline 18 & $3 \times 3 \times 4-\mathrm{Cl}$ & 185 & 25.9 & 5577 & $4244 \pm 370$ \\
\hline 20 & & & & & $410 \pm 73$ \\
\hline
\end{tabular}




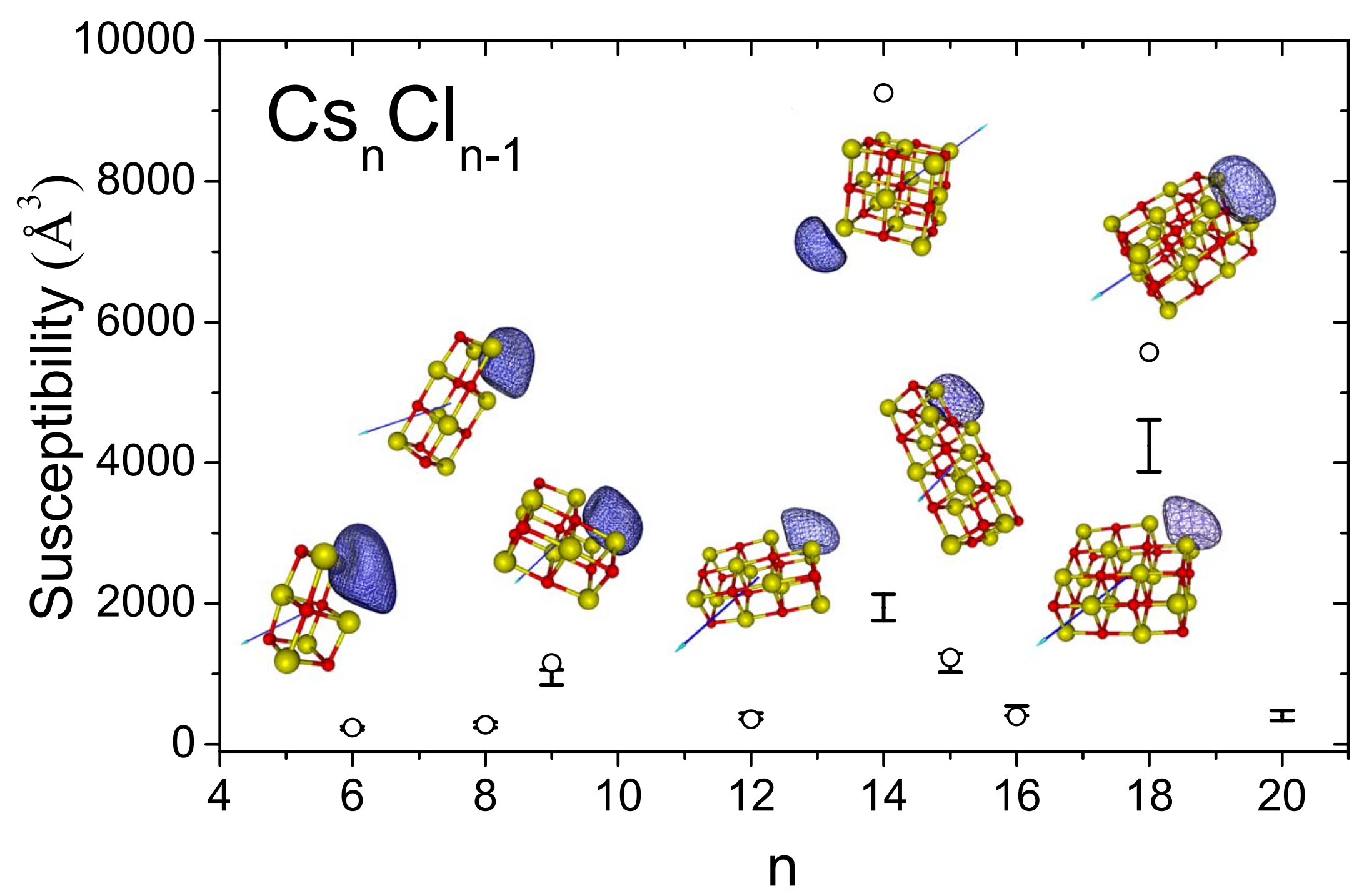

Fig. 1 


\begin{tabular}{|c|c|c|c|c|}
\hline \multicolumn{5}{|c|}{$\mathrm{Cs}_{8} \mathrm{Cl}_{7}$} \\
\hline $\begin{array}{l}\text { (a) } \Delta \mathrm{E}=0.00 \mathrm{eV} \\
\chi=278 \AA^{3}\end{array}$ & $\begin{array}{l}\text { (b) } \Delta \mathrm{E}=0.17 \mathrm{eV} \\
x=578 \AA^{3}\end{array}$ & $\begin{array}{l}\text { (c) } \Delta \mathrm{E}=0.22 \mathrm{eV} \\
\chi=466 \AA^{3}\end{array}$ & $\begin{array}{l}\text { (d) } \Delta \mathrm{E}=0.60 \mathrm{eV} \\
\chi=355 \AA^{3}\end{array}$ & $\begin{array}{l}\Delta \mathrm{E}=1.07 \mathrm{eV} \\
\chi=8929 \AA^{3}\end{array}$ \\
\hline
\end{tabular}

\begin{tabular}{|c|c|c|c|c|}
\hline \multicolumn{1}{|c|}{} & & \\
\hline
\end{tabular}

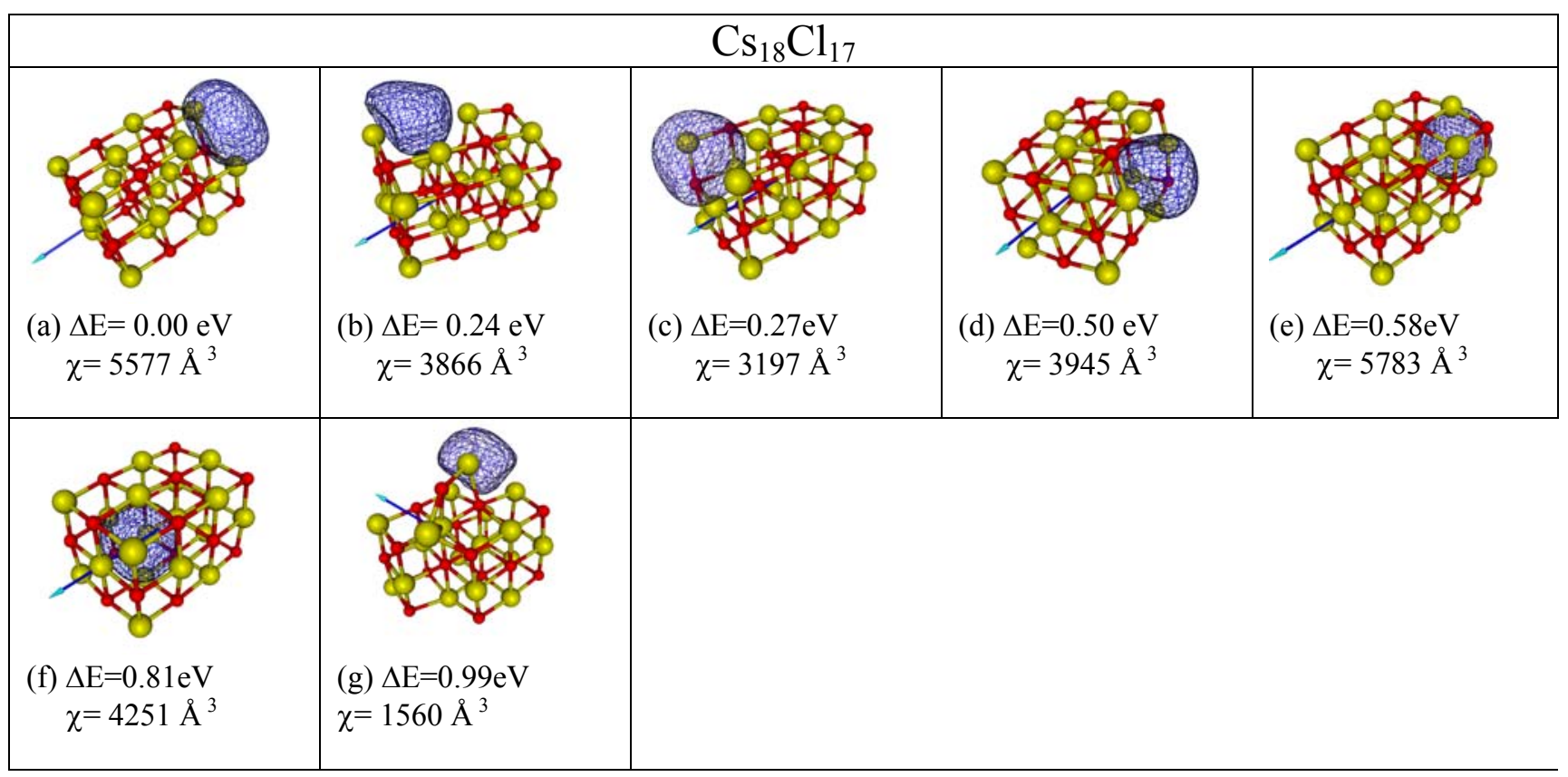

Fig. 2 